\title{
Migration dates at Eyre Bird Observatory: links with climate change?
}

\author{
Lynda E. Chambers* \\ Bureau of Meteorology Research Centre, GPO Box 1289, Melbourne, Victoria 3001, Australia
}

\begin{abstract}
In contrast to the Northern Hemisphere, relatively little is known about the influence of climate, in particular climate change, on the timing of bird migration in Australia. This paper examines a new dataset, comprising daily abundance records for 8 landbird species at Eyre Bird Observatory (EBO), Western Australia, for the period 1984 to 2003. Five of the 8 species were present at Eyre for only part of the year, while the 3 species present all year round exhibited seasonal changes in abundance. For most species, changes in migration dates were related to observed changes in the regional climate; 3 species showed no trend in migration timing, and these had no regular period of absence from EBO. Of the remaining species, the Purple-crowned Lorikeet Glossopsitta porphyrocephala and Grey Fantail Rhipidura fuliginosa showed strong trends in arrival dates: both winter visitors arrived suddenly at EBO and earlier over time, with lorikeets arriving earlier in years of warmer night-time temperatures. Two species, Fork-tailed Swift Apus pacificus and Rainbow Beeeater Merops ornatus, had strong trends in departure dates and were summer visitors. These species responded differently to warming night-time temperatures, perhaps reflecting their breeding characteristics. The Budgerigar Melopsittacus undulatus arrived and departed suddenly and showed no trend in migration timing, though wetter years corresponded to earlier arrivals. Consistent with

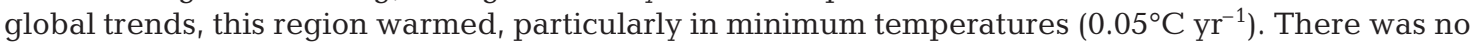
trend in rainfall.
\end{abstract}

KEY WORDS: Migration dates $\cdot$ Climate change $\cdot$ Phenology $\cdot$ Australia $\cdot$ Birds Resale or republication not permitted without written consent of the publisher

\section{INTRODUCTION}

Consistent with global temperature trends, Australia's average temperature has increased $0.7^{\circ} \mathrm{C}$, over the period 1910 to 1999, with the largest increases occurring since 1950 (Collins et al. 2000, Nicholls 2003). In addition, there is increasing evidence that the anomalously high temperatures experienced during the 20th century have been associated with changes in many natural systems, including the lengthening of growing seasons and alterations in the phenology of flowering and breeding of many species (Walther et al. 2002, Parmesan \& Yohe 2003, Root et al. 2003).

In the Northern Hemisphere, regional warming has also been linked to changes in the timing of landbird migration (e.g. Sparks \& Menzel 2002, Sparks \& Smithers 2002, Butler 2003, Parmesan \& Yohe 2003, Donnelly et al. 2004); the timing of spring migration is strongly tied to weather variations (Lehikoinen et al.
2004), with many species now arriving earlier (Sparks \& Menzel 2002, Butler 2003). Less understood, and more variable, is the timing of autumn migration, with some species migrating earlier with warming temperatures and others delaying their migration (Lehikoinen et al. 2004).

Little is currently understood about large-scale movement and migration in Australian landbirds (Chan 2001, Griffioen \& Clarke 2002), particularly in relation to climate influences (Chambers et al. 2005). Australia has a high proportion of endemic species, which have already adapted to a highly variable climate system (IPCC 2001). Climate change impacts observed for northern hemisphere species may, therefore, not be directly translatable to Australian species.

As far as I am aware, the only Australian study of the timing of bird migration related to changes in climate is for an alpine region of eastern Australia (Green \& Pickering 2002), where 7 of the 11 species studied are 
now arriving ca. 1 mo earlier (1980s and 1990s compared to the 1970s).

Using data provided by the Eyre Bird Observatory, this paper examines migration dates of 8 species of landbirds in a semi-arid environment, investigating the influence of climate change on the timing of migration and highlighting where changes in migration dates are consistent, or otherwise, with results found in the Northern Hemisphere.

\section{MATERIALS AND METHODS}

\subsection{Eyre Bird Observatory data}

The Eyre Bird Observatory (EBO) was the first bird observatory to be established by Birds Australia (a partner organization of BirdLife International), with work commencing in 1977, and is located in the Nuytsland Nature Reserve, at the southern edge of the Nullarbor Plain, Western Australia $\left(32^{\circ} 14^{\prime} 47^{\prime \prime} \mathrm{S}\right.$, $\left.126^{\circ} 18^{\prime} 03^{\prime \prime} \mathrm{E}\right)$. The main vegetation group around the observatory is Mallee woodlands and shrublands on dunes. However, this is a region of rapid biogeographic changes, with Open Grassland and Mallee occurring nearby. Although the observatory is within the semi-arid zone, it is close to the arid zone boundary, bordering Mediterranean and non-seasonal climate zones. The observatory is part of the Bureau of Meteorology's network of weather stations.

Throughout the year daily bird sightings are recorded in the EBO Daily Bird Log. Daily counts of 8 species (listed in Table 1) were obtained from the observatory, covering the period June 1, 1984 (6 species; the other 2 species commencing on September 1, 1984 and October 1, 1984) to December 31, 2003. These species were selected as their numbers are known to vary greatly throughout the year, with 5 of the species absent from EBO for a number of months each year.
Five of the 8 species are Australian endemics (Purple-crowned Lorikeet, Australian Ringneck, Budgerigar, White-fronted Honeyeater, White-fronted Chat). The Purple-crowned Lorikeet and Australian Ringneck are variously considered nomadic, resident or possibly sedentary (in the case of the Australian Ringneck), their movements related to rainfall or flowering and fruiting of food trees (Higgins 1999). Little is known of the movements of the Budgerigar, though they are expected to have both regular and irregular components and may be controlled by rainfall and possibly temperature (Higgins 1999). There may be a seasonal population shift of the Budgerigar southwards in summer and northwards in winter and towards the coastal areas during drought (Higgins 1999). The White-fronted Honeyeater is most often found in the arid zone, but can also be found in the semi-arid zone and some coastal regions (Higgins et al. 2001), such as the area around EBO. This is a species that moves around a lot, though the extent and patterns of movement are not understood. However, in areas of consistent flowering, such as EBO, the movements of the White-fronted Honeyeater have a regular seasonality (Higgins et al. 2001). In the arid and semi-arid zones, the White-fronted Chat may move inland during winter, returning to the cooler more humid coastal regions, such as EBO, when the ambient temperatures become too high (Higgins et al. 2001).

Of the remaining species, only the Fork-tailed Swift is absent from Australia for part of the year, returning to its breeding grounds in Asia. Movements within the Australian region are poorly known (Higgins 1999). The Rainbow Bee-eater and Grey Fantail are widespread on the Australian mainland. The Rainbow Beeeater is migratory in the southern part of its range, moving north in winter (Higgins 1999). None of the species are listed as threatened and, with the exception of the Grey Fantail, can appear in reasonably high numbers around EBO (Fig. 1).

Table 1. Species for which daily records were provided. Also given is the status of these species at Eyre Bird Observatory (RAOU 1996) and months in which these species were present at the observatory during this study

\begin{tabular}{|lll|}
\hline Species & Status & Present \\
\hline $\begin{array}{l}\text { Purple-crowned Lorikeet Glossopsitta } \\
\text { porphyrocephala }\end{array}$ & Visitor, mainly in winter & Jan-Sep \\
$\begin{array}{l}\text { Australian Ringneck Barnardius zonarius } \\
\text { Budgerigar Melopsittacus undulatus }\end{array}$ & Regular visitor & All months \\
Fork-tailed Swift Apus pacificus & Breeding visitor at times of good rainfall & Oct-Jan \\
Rainbow Bee-eater Merops ornatus & Summer visitor, usually preceding storms or poor weather & Jan-Apr \\
White-fronted Honeyeater Phylidonyris albifrons & Visitor, sometimes in large numbers & Sep-Mar \\
White-fronted Chat Epthianura albifrons & Visitor & All months \\
Grey Fantail Rhipidura fuliginosa & Regular winter visitor & All months \\
\end{tabular}



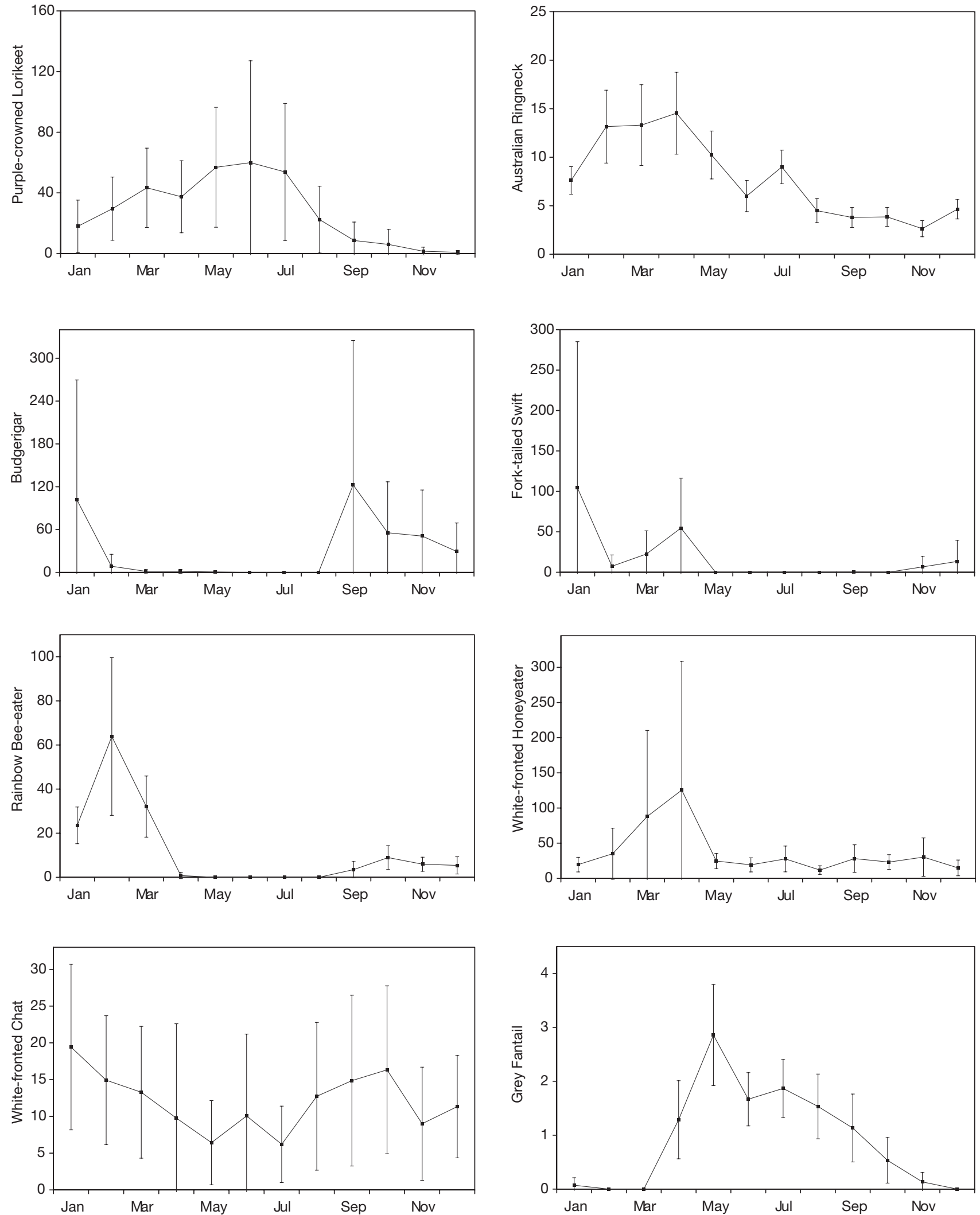

Fig. 1. Mean monthly maximum abundance for the 8 species, together with $95 \%$ confidence intervals for the mean. The wider the confidence limit the greater the year-to-year variability in the maximum number of that species seen within that month 
For most species and most days, counts were made of the number of birds seen on that day, with the maximum number of each species seen recorded in the Daily Bird Log. On some occasions, however, only presence/absence information was provided. This was particularly evident in the earliest years on record. No records were made by the observatory of how many people contributed each day to the bird counts or the proportion of time spent searching for birds. Search effort variation has the potential to impact on the number of birds recorded, and this is acknowledged by Birds Australia (the organisation responsible for the records). In particular, Birds Australia note that variations in the number of birds seen throughout the year, and between years, are likely to be influenced by 'changes in weather, daily activities and the number of visitors available to assist in the observations' (RAOU 1996). To compensate for search effort variation, species that are relatively conspicuous and commonly observed were selected for this study, largely ensuring that, at a minimum, presence/absence data were available, if not a daily count.

Given the observatory's location, it is likely to attract birds during dry periods as water is supplied in birdbaths.

\subsection{Climate data}

The EBO records daily minimum and maximum temperature and rainfall (Bureau of Meteorology site number 011019). These are converted to monthly totals for rainfall and monthly averages for temperature; however, some temperature observations are missing within some months and years (particularly during the earlier years of the study period).

The EBO is not part of the Bureau of Meteorology's high quality temperature or rainfall datasets (Lavery et al. 1997, Collins et al. 2000, Della-Marta et al. 2004). For this reason, comparisons were also made with quality-controlled gridded rainfall and temperature data (as described in Jones 1999) over a wider region, encompassing the observatory $\left(30\right.$ to $35^{\circ} \mathrm{S}, 123$ to $130^{\circ} \mathrm{E}$; land values only). This dataset is complete for the period of this study. Fig. 2 shows the mean monthly rainfall and temperature variation for the region. Both point (local) temperature and rainfall data and gridded (regional) data have the potential to influence species abundance at EBO.

\subsection{Analysis}

Dates of arrival at, and departure from, the observatory are loosely referred to as migration dates, although, for some species, movement may be either migratory (predictable seasonal movement pattern) or nomadic (movement according to suitable conditions). For some species, part of the population is resident while other individuals are migrants (Chan 2001). Partial migration tends to occur when the climate and/or resource availability is highly variable between years, but not severe enough to restrict the entire population (Chan 2001).

To determine which species were regular seasonal visitors to EBO, the daily records were summarised according to month. For species that were absent for part of the year, annual arrival dates, annual departure dates and the length of the season that the species were present were calculated. For most species it was also possible to calculate the timing of the peak abundance.

The date of the first arrival (departure) of a bird species in (from) an area has been used to describe arrival (departure) times of migratory species (Lehikoinen et al. 2004). Defining arrival (departure) dates in this way, however, may not reflect the migratory behaviour of the entire population and other measures have been proposed, such as mean (or median) arrival (Lehikoinen et al. 2004). It was not possible to calculate mean (or median) arrival dates for birds at EBO as the bird populations were not closely followed and individuals were not identified. Several alternative approaches were adopted for defining the arrival, departure and peak dates as, for some species, birds would be seen once and then not seen again for a number of days (or, in extreme cases, months). The 'true' arrival, departure or peak dates (better reflecting the migratory behaviour of the entire population) should be encompassed in at least one of the measures, and by comparing the indices information is gained on the regularity of initial (final) records.

Annual arrival dates were defined using 4 methods: (1) the date the species was first recorded in the year (A1) ('first arrival' in Lehikoinen et al. 2004); (2) the date of the third record for the year (A2), chosen because the first few records of a species in a season may not be representative of arrival dates of the species as a whole (by the third arrival date the species was more likely to be seen on subsequent dates and hence reflect the migratory behaviour of the entire population); (3) the date of the first consecutive records of the species for the year (A3), again, a measure of consistency of arrival dates; and (4) the date of the first run of 3 consecutive increasing (or constant) records for the year (A4).

Similar methods were used to define the annual departure dates: (1) the date the species was last recorded in the year (D1); (2) the date of the third-to- 


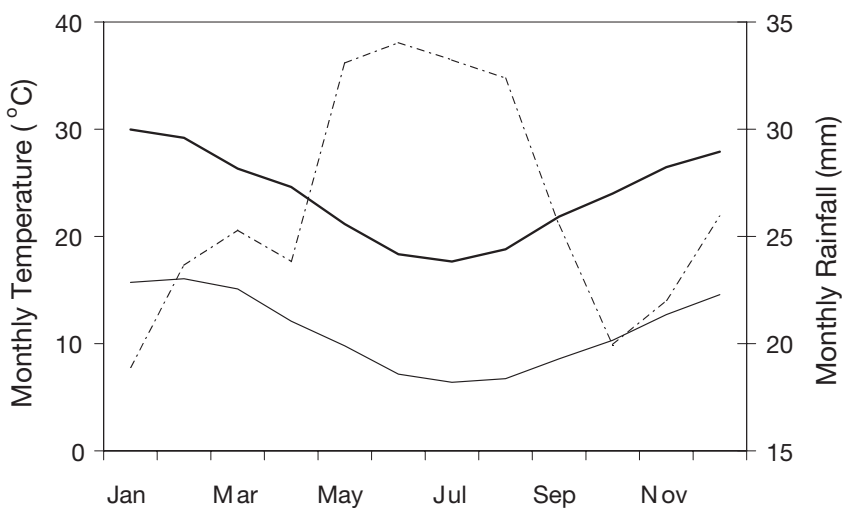

Fig. 2. Mean monthly rainfall (dashed line), maximum temperature (bold line) and minimum temperature (thin line) for the region bounded by 30 to $35^{\circ} \mathrm{S}$ and 123 to $130^{\circ} \mathrm{E}$. Averages are based on the period January 1984 to December 2003

last record for the year (D2); (3) the date of the last consecutive records of the species for the year (D3); (4) the date of the last run of 3 consecutive decreasing (or constant) records for the year (D4).

Peak abundance was defined as (1) the mid-point between the first and last records for the year (P1), (2) the mid-point between the third and third-to-last records for the year (P2), (3) the date the maximum number of that species was recorded (P3), or (4) the date the maximum number of that species was recorded using a 5-point moving average (P4).

The first 2 measures of peak abundance assume that the number of a particular species increases up to the peak and then decreases again, in a symmetrical fashion. These methods were considered because-in some years, for some species - it was not possible to calculate 'true' peak abundance using the last 2 methods as only presence/absence data were recorded.

The length of season was defined as (1) the difference between the date of the last record and the date of the first record for the year (L1) or (2) the difference between the date of the third-to-last record and the date of the third record for the year (L2).

Measures such as A1 and D1 only tell us about the ends of the migration distribution and how these might respond to climate variability. By including additional measures, such as peak date and season length, we obtain a more complete picture of how migration dates may be changing over time.

Trends in each of the variables (A1 to A4, D1 to D4, P1 to P4 and L1 and L2) were calculated using simple linear regression with the year as the explanatory variable and the resultant $\mathrm{p}$-values used to determine statistical significance. Using both annual and seasonal data, trends over time were also calculated for rainfall, and maximum and minimum temperature.

\section{RESULTS}

Fig. 1 illustrates the monthly pattern of peak abundance for each species and Table 1 indicates the months in which the species were seen at EBO. Five of the 8 species (the Purple-crowned Lorikeet, Budgerigar, Fork-tailed Swift, Rainbow Bee-eater and Grey Fantail) had clearly defined periods of absence from EBO, and it was possible to calculate arrival and departure dates. The other 3 species (the Australian Ringneck, White-fronted Honeyeater and White-fronted Chat) had clear peaks in annual abundance, but no clearly defined period of absence from EBO. In some cases it was not possible to determine the date of peak abundance because, for some species (e.g. the Grey Fantail) and some months, there was a high proportion of presence/absence data only, masking potentially high abundance days. However, the use of alternative measures of peak abundance helped to overcome some of these limitations. The use of presence/absence data only affects calculations of runs of consecutively increasing or decreasing records of the species (A4 and D4) and measures of peak abundance using the maximum number of birds recorded (P3 and P4).

Trends in the date of peak abundance and-excluding the 3 species that were not seasonally absentarrival and departure dates and length of the season were generally consistent, in terms of both magnitude and sign, for A1 to A4, D1 to D4, P1 to P4 and L1 and L2 (Table 2). For the Budgerigar, Fork-tailed Swift and the Grey Fantail there were some years with few observations, particularly consecutive daily recordings, and trends in A4 and D4 were not calculated. Budgerigars were seen much less frequently in the later years of the study period, and it was not possible to calculate many of the trends in timing for this species. The Grey Fantail was generally seen in very low numbers when present at EBO and, therefore, no trends in the dates of peak abundance were calculated.

Most of the trends in migration dates were moderate in magnitude (-4.93 to $6.45 \mathrm{~d} \mathrm{yr}^{-1}$; Table 2), reflecting the high year-to-year variability in arrival and departure dates. For some species, the pattern of arrival and departure also varied between years, with differing levels of skewness in the abundance-time distributions; it was only possible to calculate these for the Purple-crowned Lorikeet, Budgerigar and Fork-tailed Swift. Skewness coefficients ranged between 1.2-4.7, $0-4.2$ and $0-3.2$, respectively).

Over the study period, there was a general tendency for species to arrive earlier (Table 2; 13 out of 16 of the arrival date indices were negative). The Fork-tailed Swift also departed earlier (3.68 to $4.93 \mathrm{~d} \mathrm{yr}^{-1}$ ), while the Rainbow Bee-eater departed later (0.97 to $2.65 \mathrm{~d}$ $\mathrm{yr}^{-1}$ ), resulting in a longer season length (the period 
Table 2. Trends $\left(\mathrm{d} \mathrm{yr}^{-1}\right)$ in annual arrival date, annual departure date, peak abundance and length of season present; negative values indicate an earlier arrival/departure and positive values a later arrival/departure over time. Species codes: PCL, Purplecrowned Lorikeet; AR, Australian Ringneck; B, Budgerigar; FTS, Fork-tailed Swift; RB, Rainbow Bee-eater; WFHe, White-fronted Honeyeater; WFC, White-fronted Chat; GF, Grey Fantail. A1 to A4 (D1 to D4) represent arrival (departure) dates defined according to first (last), third (third-to-last), first (last) consecutive and first (last) run of 3 consecutive increasing (decreasing) or constant records, respectively. P1 (P2) is the mid-point between A1 and D1 (A2 and D2), P3 is the date of maximum number of that species and P4 is the date of the maximum number of that species after a 5-point moving average was applied to the counts. The length of season, L1 and L2, is defined as D1 - A1 and D2 - A2, respectively. Trends significant at the $5 \%$ level are in bold. *: too few years had data of the type required to obtain trends; -: present all year, i.e. no arrival/departure dates

\begin{tabular}{|c|c|c|c|c|c|c|c|c|c|c|c|c|c|c|}
\hline & \multicolumn{4}{|c|}{ Arrival } & \multicolumn{4}{|c|}{ Departure } & \multicolumn{4}{|c|}{ Peak date } & \multicolumn{2}{|c|}{ Season length } \\
\hline & A1 & $\mathrm{A} 2$ & A3 & $\mathrm{A} 4$ & D1 & D2 & D3 & D4 & $\mathrm{P} 1$ & $\mathrm{P} 2$ & P3 & P4 & L1 & $\mathrm{L} 2$ \\
\hline PCL & -1.06 & -2.68 & -3.99 & -2.62 & -1.37 & 1.37 & -0.37 & -0.21 & -1.22 & -0.64 & 2.04 & 1.98 & -0.30 & 4.05 \\
\hline $\mathrm{AR}$ & - & - & - & - & - & - & - & - & - & - & 2.59 & -1.28 & - & - \\
\hline B & -0.79 & 1.13 & $*$ & * & 6.45 & * & * & * & * & * & $*$ & * & $*$ & * \\
\hline FTS & 0.40 & -2.10 & -2.34 & * & -3.68 & -4.96 & -4.93 & * & -1.64 & -3.53 & -2.62 & $*$ & -4.08 & * \\
\hline $\mathrm{RB}$ & -0.64 & -0.46 & -1.67 & 2.13 & 0.40 & 2.65 & 0.97 & * & -0.12 & 0.91 & 0.79 & 0.64 & 1.86 & 3.50 \\
\hline WFHe & - & - & - & - & - & - & - & - & - & - & 1.31 & -0.27 & - & - \\
\hline WFC & - & - & - & - & - & - & - & - & - & - & -11.26 & -14.88 & - & - \\
\hline GF & -0.55 & -0.67 & -0.52 & * & 1.19 & -0.49 & -0.06 & * & * & * & $*$ & $*$ & 2.01 & 0.58 \\
\hline
\end{tabular}

that Rainbow Bee-eaters were present at EBO lengthened by ca. $2 \mathrm{~d} \mathrm{yr}^{-1}$ ). No species showed a significant shift in the date of peak abundance (Table 2).

No statistically significant trends toward either wetter or drier conditions were observed over the study period (Table 3 ). The EBO station rainfall data aligned closely with the regional rainfall ( $\mathrm{r}=0.859, \mathrm{n}=20$ ). There was also good agreement between the maximum temperature records at EBO and those of the region $(\mathrm{r}=0.916, \mathrm{n}=20)$. A statistically weak trend towards warmer maximum temperatures was ob-

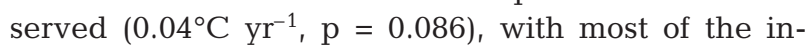
crease occurring during winter (June-July-August;

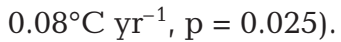

Other than for the summer period (DecemberJanuary-February), there was very little agreement between the EBO and regional minimum temperature data, particularly during the September-OctoberNovember period. Using EBO data, there was a slight

Table 3. Trends in annual rainfall $\left(\mathrm{mm} \mathrm{yr}^{-1}\right)$ and in maximum $\left(T_{\max }\right)$ and minimum $\left(T_{\min }\right)$ temperature $\left({ }^{\circ} \mathrm{C} \mathrm{yr}^{-1}\right)$. DJF: December-January-February; MAM: March-April-May; JJA: June-July-August; and SON: September-October-November. Trends significant at the $5 \%$ level are in bold

\begin{tabular}{|lcrrrr|}
\hline & Annual & DJF & MAM & JJA & SON \\
\hline EBO & & & & & \\
Rainfall & 4.72 & 3.58 & 0.99 & -1.11 & 1.60 \\
$T_{\max }$ & $\mathbf{0 . 0 9}$ & 0.03 & 0.08 & $\mathbf{0 . 1 3}$ & 0.09 \\
$T_{\min }$ & $\mathbf{- 0 . 0 5}$ & -0.04 & -0.06 & -0.08 & -0.06 \\
Regional average & & & & \\
Rainfall & 3.58 & 2.91 & 0.33 & -0.76 & 1.15 \\
$T_{\max }$ & 0.04 & 0.01 & 0.02 & $\mathbf{0 . 0 8}$ & 0.02 \\
$T_{\min }$ & $\mathbf{0 . 0 5}$ & 0.05 & $\mathbf{0 . 0 5}$ & 0.03 & $\mathbf{0 . 0 5}$ \\
\hline
\end{tabular}

indication of a decrease in minimum temperature, while the regional data indicated that it rose signifi-

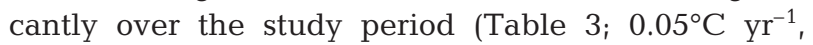
$\mathrm{p}<0.001$ ), particularly during autumn and spring. Very few temperature recordings were made prior to 1991, and this may explain some of the difference between the minimum temperature trends observed for EBO and the region.

Rainfall is a major controlling factor in the movement of the Budgerigar (Higgins 1999). When annual rainfall was high in the region surrounding EBO, the Budgerigar appeared earlier at EBO (Table $4 ; \mathrm{r}=-0.952, \mathrm{n}=7$ ). However, over the study period there were no trends in annual rainfall or in Budgerigar arrival dates. Similar results were found for the Purple-crowned Lorikeet (correlation with rainfall in the season prior to arrival, September to October: $\mathrm{r}=-0.711, \mathrm{n}=10$ ), the movement of which is influenced by eucalypt flowering (Higgins 1999). Increasing minimum temperaturesalso likely to influence the timing of eucalypt flowering (Keatley et al. 2002) - corresponded to earlier arrival dates for these lorikeets (Table $4 ; \mathrm{r}=-0.640, \mathrm{p}=0.025$ ).

The Fork-tailed Swift breeds in Asia and is a nonbreeding visitor to EBO (Higgins 1999). Although no statistically significant trend was seen in the arrival dates (or date of peak abundance) of swifts at EBO, these dates were highly correlated with regional temperature (Table 4); swifts arrive earlier and have an earlier peak abundance in warmer years. Swifts departed earlier over time (Table 2), with departure dates related to annual minimum temperature $(\mathrm{r}=$ $-0.820, \mathrm{n}=8$ ), which has been rising (Table 3). Departure of the Rainbow Bee-eater, a breeding summer visitor to EBO, occurred later over the study period (Table 2), and the dates were related to changes in 
Table 4. Correlations between species timing parameters and annual regional climate variables. Species codes as in Table 2. $T_{\max }$ and $T_{\min }$ are annual averaged maximum and minimum temperature, respectively. Trends significant at the $5 \%$ level are in bold. Correlations with arrival and departure dates are only given for species that are absent for part of the year

\begin{tabular}{|c|c|c|c|c|c|c|c|c|c|c|c|c|c|c|}
\hline & \multicolumn{4}{|c|}{ Arrival } & \multicolumn{4}{|c|}{ Departure } & \multicolumn{4}{|c|}{ Peak date } & \multicolumn{2}{|c|}{ Season length } \\
\hline & A1 & A2 & A3 & A4 & D1 & D2 & D3 & D4 & P1 & P2 & P3 & P4 & L1 & L2 \\
\hline \multicolumn{15}{|l|}{ PCL } \\
\hline Rainfall & -0.288 & 0.017 & -0.144 & -0.245 & -0.115 & 0.064 & 0.051 & 0.043 & -0.207 & 0.061 & -0.054 & -0.075 & -0.014 & 0.058 \\
\hline$T_{\max }$ & 0.286 & -0.357 & -0.138 & 0.120 & -0.020 & -0.038 & -0.209 & -0.027 & 0.076 & -0.160 & 0.089 & 0.117 & -0.110 & 0.113 \\
\hline$T_{\min }$ & -0.119 & -0.640 & -0.542 & -0.033 & -0.002 & 0.187 & -0.096 & 0.031 & -0.042 & -0.069 & 0.281 & 0.290 & 0.036 & 0.461 \\
\hline \multicolumn{15}{|c|}{ - } \\
\hline Rainfall & - & - & - & - & - & - & - & - & - & - & -0.285 & -0.325 & - & - \\
\hline$T_{\max }$ & - & - & - & - & - & - & - & - & - & - & 0.410 & 0.311 & - & - \\
\hline$T_{\min }$ & - & - & - & - & - & - & - & - & - & - & 0.318 & -0.047 & - & - \\
\hline \multicolumn{15}{|c|}{ 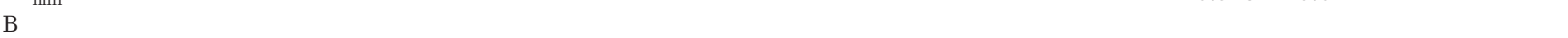 } \\
\hline Rainfall & -0.952 & -0.320 & - & - & 0.295 & - & - & - & - & - & - & - & - & - \\
\hline$T_{\max }$ & 0.702 & 0.625 & - & - & 0.644 & - & - & - & - & - & - & - & - & - \\
\hline$T_{\min }$ & -0.035 & 0.137 & - & - & 0.882 & - & - & - & - & - & - & - & - & - \\
\hline \multicolumn{15}{|l|}{ FTS } \\
\hline Rainfall & 0.615 & 0.414 & -0.361 & - & -0.117 & -0.085 & -0.711 & - & 0.351 & -0.176 & 0.172 & - & -0.628 & - \\
\hline$T_{\max }$ & -0.621 & -0.784 & -0.553 & - & -0.502 & -0.440 & -0.365 & - & -0.714 & -0.668 & -0.673 & - & 0.169 & - \\
\hline$T_{\min }$ & -0.222 & -0.800 & -0.903 & - & -0.599 & -0.820 & -0.618 & - & -0.499 & -0.888 & -0.735 & - & -0.254 & - \\
\hline \multicolumn{15}{|c|}{ - } \\
\hline Rainfall & -0.279 & 0.051 & -0.003 & 0.108 & -0.065 & 0.275 & -0.187 & -0.435 & -0.274 & 0.432 & 0.160 & 0.196 & 0.159 & 0.085 \\
\hline$T_{\max }$ & -0.158 & -0.047 & -0.245 & 0.024 & 0.181 & 0.112 & 0.717 & 0.508 & 0.035 & -0.091 & 0.215 & 0.213 & 0.627 & 0.234 \\
\hline$T_{\min }$ & -0.262 & -0.078 & -0.405 & 0.435 & 0.146 & 0.415 & 0.870 & 0.233 & 0.050 & 0.264 & 0.340 & 0.336 & 0.755 & 0.447 \\
\hline \multicolumn{15}{|l|}{ WFHe } \\
\hline Rainfall & - & - & - & - & - & - & - & - & - & - & 0.350 & 0.349 & - & - \\
\hline$T_{\max }$ & - & - & - & - & - & - & - & - & - & - & -0.321 & -0.332 & - & - \\
\hline$T_{\min }$ & - & - & - & - & - & - & - & - & - & - & -0.088 & -0.052 & - & - \\
\hline \multicolumn{15}{|l|}{$\begin{array}{r}{ }_{\min } \\
\mathrm{WFC}\end{array}$} \\
\hline Rainfall & - & - & - & - & - & - & - & - & - & - & -0.514 & -0.660 & - & - \\
\hline$T_{\max }$ & - & - & - & - & - & - & - & - & - & - & 0.106 & 0.319 & - & - \\
\hline$T_{\min }$ & - & - & - & - & - & - & - & - & - & - & -0.305 & -0.211 & - & - \\
\hline \multicolumn{15}{|c|}{$0.000-0.211$} \\
\hline Rainfall & -0.115 & -0.058 & -0.014 & - & 0.016 & -0.351 & 0.150 & - & - & - & - & - & 0.038 & -0.317 \\
\hline$T_{\max }$ & -0.161 & -0.090 & -0.047 & - & 0.292 & 0.371 & -0.133 & - & - & - & - & - & 0.319 & 0.509 \\
\hline$T_{\min }$ & -0.444 & -0.145 & -0.104 & - & 0.350 & 0.188 & 0.055 & - & - & - & - & - & 0.426 & 0.352 \\
\hline
\end{tabular}

annual minimum temperature $(\mathrm{r}=0.870, \mathrm{n}=12)$ and annual maximum temperature $(\mathrm{r}=0.719, \mathrm{n}=12)$. This resulted in a longer season at Eyre (Table 2).

Movement in the White-fronted Chat, in the arid and semi-arid zones, is influenced by rainfall (Higgins et al. 2001), with peak abundance being earlier in years of high rainfall. No rainfall trends were observed over the study period (Table 3) and, correspondingly, no trends were observed in the date of peak abundance in chats (Table 2). Migration timing in the Australian Ringneck, White-fronted Honeyeater and Grey Fantail did not appear to be related to climate variables (Table 4).

\section{DISCUSSION}

Rainfall trends over many regions of Australia are currently weak, due to high interannual variability (Smith 2004), as was seen in the region surrounding EBO in this study. The results found in this study were consistent with the annual, and 6-monthly, rainfall trends for the region surrounding EBO found by Smith (2004). The warming trends, found in this study for the EBO region, are consistent with an overall warming trend in minimum temperature across Australia and in maximum temperature in central and western parts of the continent found by Della-Marta et al. (2004).

Species that have high abundance and are regularly recorded within the months that they are present at EBO should give consistent trend estimates, regardless of the definition of migration timing used. Although the magnitude of the trend often varied between the different migration definitions, the sign of the trends was generally consistent, particularly for arrival and departure dates and for the length of season. For most species in this study, however, there was often a considerable number of days between records, particularly at the start and end of their season at EBO. This resulted in a small number of conflicting trends, particularly for peak abundance. First arrival date (A1) and 
last departure date (D1) are expected to have large random variances (Lehikoinen et al. 2004); however, they are easy and cheap to observe. For many species in this study, A1 or D1 gave similar results to the other measures of migration timing.

Why some species had trends in arrival or departure dates, and others did not, is likely to be related (at least in part) to their patterns of arrival or departure, and is likely to have a biological basis. From Fig. 1, we see that species that arrived suddenly (i.e. zero recorded the month before a relatively large influx of birds) but departed gradually, such as the Purple-crowned Lorikeet and the Grey Fantail, had strong trends in their arrival dates (Table 2). These were the only species that were annual winter visitors (Table 1). The Purplecrowned Lorikeet generally arrived at EBO earlier than the Grey Fantail, particularly in years with warm minimum temperature, with both species showing a trend towards earlier arrival dates over time. The movement of the lorikeets is thought to be related to flowering or fruiting of trees, such as eucalypts (Higgins 1999).

In contrast, species that arrived gradually but departed suddenly (the Fork-tailed Swift and the Rainbow Bee-eater) had strong trends in their departure dates (Table 2). The Budgerigar, which both arrived and departed suddenly, did not exhibit any strong trends in arrival or departure dates (Table 2), perhaps due to the high year-to-year variability in abundance of this species and reliance on rainfall as an initiator of movement (Higgins 1999). All 3 species are summer visitors to $\mathrm{EBO}$, the Budgerigar and Rainbow Bee-eater arriving in spring and the Fork-tailed Swift during summer (Table 1). Departure dates of swifts, and to a lesser extent bee-eaters, appeared to be related to regional night-time temperatures, with warmer nights corresponding to an earlier departure in swifts and a later departure in bee-eaters. Why these species react in a different way to warmer minimum temperatures may be linked to their breeding biology. The Rainbow Bee-eater breeds at EBO and may take advantage of the 'longer summer' by increasing the time spent in the region; in contrast, the Fork-tailed Swift breeds in Asia. There was a tendency for both arrival (not statistically significant) and departure dates of the swifts to become earlier over time, linked with increasing nighttime temperature (as did the peak abundance date; Table 4). This may reflect a shift in their migration timing distribution, and may be related to changes in temperature at their breeding locations.

The 3 species that displayed no regular seasonal absence from EBO (Table 1) showed no trend in the timing of migration, measured by the date of peak abundance. Only the timing of peak abundance in the White-fronted Chat was correlated with any of the climate variables (the peak in abundance occurring earlier in years of high rainfall). Movement in this species is influenced by winter rainfall, with movement to the coastal zones during the warmer months (Higgins et al. 2001). The extent, and patterns, of movement of the White-fronted Honeyeater are not well understood (Higgins et al. 2001). This species is a partial migrant, with variations in local climate and food conditions likely to influence its movement patterns (Chan 2001). This species has also been described as having a 'confused' pattern of movement (Griffioen \& Clarke 2002). Patterns of movement in the Australian Ringneck are also poorly understood, the species being considered by some as resident and others as possibly sedentary or nomadic (Higgins 1999).

Comparable with Northern Hemisphere studies (Lehikoinen et al. 2004), in this study there was less consistency in the sign of autumn migration trends (departure timing for the Budgerigar, Fork-tailed Swift and Rainbow Bee-eater and arrival timing for the Grey Fantail), than for spring migration (all species migrating in spring tended to do so earlier over time, though most trends were not statistically significant). Changes in temperature were generally more closely associated with arrival and departure dates than rainfall.

It should be noted that there are some limitations to the analyses shown here. There were variations in the sampling effort: the number of visitors available to assist in the observations varied daily, seasonally and annually. By selecting species that were relatively conspicuous and had relatively high abundance when present at EBO, the influence of variation in observer effort is minimised, particularly when considering migration timing definitions that are independent of raw counts, such as first arrival (last departure), third arrival (third-to-last departure) date.

The relatively short period of recording $(<20 \mathrm{yr})$ may make the trends less stable (compared to trends calculated using more years of data, were they available) and, consequently, the findings may be influenced by decadal climate variability rather than climate change. This is fairly typical of phenological studies in Australia, which (unlike many of those from the Northern Hemisphere) tend to have short historical records. On a positive note, there were no major changes in land use patterns or land management practices over the study period, as the EBO is located in the Nuytsland Nature Reserve.

\section{CONCLUSIONS}

Of the 8 species considered in this study only 3 showed no trend in migration timing and all of these had no regular period of absence from EBO. Of the 
remaining species, the Purple-crowned Lorikeet and Grey Fantail showed strong trends in arrival dates; both winter visitors arrived suddenly at EBO and earlier over time. Timing of arrival at EBO for lorikeets was related to night-time temperatures. Two species (the Fork-tailed Swift and Rainbow Bee-eater) had strong trends in departure dates and were summer visitors. These species responded differently to warming night-time temperatures, perhaps reflecting their breeding characteristics (one breeding in the austral summer and the other in Asia). The Budgerigar arrived and departed suddenly and showed no trend in migration timing. As has been seen in several Northern Hemisphere studies (reviewed in Lehikionen et al. 2004), many of the changes in migration dates at EBO corresponded to changes in regional temperatures.

The EBO is on the southern edge of the Australian continent, adjoining the Great Australian Bight. If temperatures in this region continue to increase, the observatory may see further changes in abundance, timing and composition of bird species. Once critical temperature thresholds are reached, which are currently unknown, birds will only be able to travel to cooler southern regions of Australia over considerable distances westwards or eastwards. This may be difficult for some species, as regular east-west migration, over significant distances, is uncommon in Australian birds (Chan 2001).

Given the limited information available on the influence of climate change on the migration dates of Australian landbirds (Chambers et al. 2005), this paper adds to our knowledge, while also highlighting a need for further research in this area.

Acknowledgements. The author wishes to thank the reviewers of this paper, S. McNee for organising access to the EBO data, C. Van Delft, and her daughter Lisa, for the painstaking task of entering the Daily Bird Log into a database format and to the many observers that made the Daily Bird Log possible.

\section{LITERATURE CITED}

Butler CJ (2003) The disproportionate effect of global warming on the arrival dates of short-distance migratory birds in North America. Ibis 145:484-495

Chambers LE, Hughes L, Weston MA (2005) Climate change and its impact on Australia's avifauna. Emu 105:1-20

Chan K (2001) Partial migration in Australian landbirds: a review. Emu 101:281-292

Collins DA, Della-Marta PM, Plummer N, Trewin BC (2000) Trends in annual frequencies of extreme temperature

Editorial responsibility: Otto Kinne,

Oldendorf/Luhe, Germany events in Australia. Aust Meteorol Mag 49:277-292

Della-Marta P, Collins D, Braganza K (2004) Updating Australia's high-quality annual temperature dataset. Aust Meteorol Mag 53:75-93

Donnelly A, Jones MB, Sweeney J (2004) A review of indicators of climate change for use in Ireland. Int $\mathrm{J}$ Biometeorol 49:1-12

Green K, Pickering CM (2002) A potential scenario for mammal and bird diversity in the Snowy Mountains of Australia in relation to climate change. In: Korner C, Spehn E (eds) Global mountain biodiversity: changes and threats. Springer-Verlag, Berlin, p 241-249

Griffioen PA, Clarke MF (2002) Large-scale bird-movement patterns evident in eastern Australian atlas data. Emu 102: 99-125

Higgins PJ (ed) (1999) Handbook of Australian, New Zealand and Antarctic Birds, Vol 4: Parrots to Dollarbird. Oxford University Press, Melbourne

Higgins PJ, Peter JM, Steele WK (eds) (2001) Handbook of Australian, New Zealand and Antarctic Birds, Vol 5: Tyrant-Flycatchers to Chats. Oxford University Press, Melbourne

IPCC (Intergovernmental Panel on Climate Change) (2001) Climate change 2001: impacts, adaptation, and vulnerability. Contribution of Working Group II. McCarthy JJ, Canziani OF, Leary NA, Dokken DJ, White KS (eds). Cambridge University Press, Cambridge

Jones DA (1999) Characteristics of Australian land surface temperature variability. Theor Appl Climatol 63:11-31

Keatley MR, Fletcher TD, Hudson IL, Ades PK (2002) Phenological studies in Australia: potential application in historical and future climate analysis. Int J Climatol 22: $1769-1780$

Lavery BM, Joung G, Nicholls N (1997) An extended highquality historical rainfall dataset for Australia. Aust Meteorol Mag 46:27-38

Lehikoinen E, Sparks TH, Zalakevicius M (2004) Arrival and departure dates. In: Møller A, Fiedler W, Berthold P (eds) Birds and climate change. Advances in ecological research, Vol 35. Elsevier, Amsterdam, p 1-31

Nicholls N (2003) Continued anomalous warming in Australia. Geophys Res Lett 30(7):1370

Parmesan C, Yohe G (2003) A globally coherent fingerprint of climate change impacts across natural systems. Nature 421:37-42

RAOU (Royal Australasian Ornithologists Union) (1996) Eyre Bird Observatory Report 6 1988-1992. Report No. 97 , RAOU, Melbourne

Root TL, Price JT, Hall KR, Schneider SH, Rosenzweig C, Pounds JA (2003) Fingerprints of global warming on wild animals and plants. Nature 421:57-60

Smith I (2004) An assessment of recent trends in Australian rainfall. Aust Meteorol Mag 53:163-173

Sparks TH, Menzel A (2002) Observed changes in seasons: an overview. Int J Climatol 22:1715-1725

Sparks TH, Smithers RJ (2002) Is spring getting earlier? Weather 57:157-166

Walther GR, Post E, Convey P, Menzel A and 5 others (2002) Ecological responses to recent climate change. Nature 416:389-395

Submitted: February 25, 2005; Accepted: July 7, 2005

Proofs received from author(s): August 3, 2005 